\title{
Radio Formats by Administrative Choice
}

\section{Matthew L. Spitzer $\dagger$}

Did you ever have to make up your mind

To pick up on one and leave the other behind

It's not often easy and not often kind

Did you ever have to make up your mind?

Before anyone may lawfully broadcast radio transmissions in the United States, he must obtain a license from the Federal Communications Commission. ${ }^{2}$ The Commission may issue a license only if the "public convenience, interest, or necessity will be served thereby." If the holder of a broadcast license ("licensee") attempts to renew the license upon its expiration ${ }^{4}$ or to transfer it, the FCC may issue a renewal license or approve the proposed transfer ${ }^{5}$ only if the renewal or transfer would meet the same public interest standard.

$\dagger$ Assistant Professor of Law, Northwestern University. The author gratefully acknowledges the valuable assistance and ideas of Professors Robert Bennett and Daniel Polsby of Northwestern University School of Law; Professors Alan Schwartz and Michael Levine of the University of Southern California Law Center and the California Institute of Technology; and Professor Richard Epstein of the University of Chicago Law School. William Stein, Northwestern University School of Law class of 1982, provided valuable research assistance. The author accepts responsibility for any error.

1 Copyright 1965, 1966 by The Hudson Bay Music Co.; written by John Sebastian; used by permission; all rights reserved.

247 U.S.C. $\$ 301$ (1976).

Id. $\S 307(\mathrm{a})$.

- Broadcast licenses have a maximum duration of three years. Id. $\S 307(\mathrm{~d})$.

s Id. $\S 310(\mathrm{~d})$. 
Occasionally, a licensee will attempt to transfer his license to someone who wishes to change the format ${ }^{8}$ of the station operating under the license. A series of cases in the Court of Appeals for the District of Columbia Circuit ${ }^{\gamma}$ has held that, if certain conditions exist, the FCC may not approve such a transfer application without holding hearings on whether the transfer would serve the public interest. If the format to be abandoned is unique as well as financially viable, and the abandonment is protested by a significant sector of the listening public, the Commission must hold a hearing. The FCC cannot approve the transfer unless the hearing shows that the proposed format better serves the public interest. This rule will be termed the WEFM doctrine, after Citizens Committee to Save WEFM v. FCC, ${ }^{8}$ the leading case. In 1976 the FCC issued a Policy Statement ${ }^{9}$ purportedly rejecting the WEFM doctrine and substituting unfettered licensee choice of radio entertainment formats. Last year the D.C. Circuit invalidated the Policy Statement and reaffirmed the WEFM doctrine. ${ }^{10}$

This article reviews the dispute between the FCC and the D.C. Circuit.1 It then uses axiomatic social choice theory ${ }^{12}$ to analyze the options available to the FCC in license transfer hearings under the WEFM doctrine. This analysis urges extreme caution in accepting the WEFM doctrine. Implementing WEFM would require the FCC to accord greater than equal weight to the preferences of certain groups, to prefer the status quo, or to prefer certain formats for paternalistic reasons; neither the FCC nor the District of Columbia Circuit has even considered the legality or desirability of

- "Format" as used in this article subsumes the style, tone, and contents of radio stations' entertainment programming. Classical music, country and western, disco, and all news are examples of modern radio formats. For the contention that every radio station's entertainment programming is a unique format, see Development of Policy re: Changes in the Entertainment Formats of Broadcast Stations, 57 F.C.C.2d 580, 594-95 (1976) (notice of inquiry) (Robinson, Comm'r, concurring). This article presumes that two different stations may broadcast two variations of the same format.

7 Citizens Comm. to Save WEFM v. FCC, 506 F.2d 246 (D.C. Cir. 1974) (en banc); Citizens to Keep Progressive Rock v. FCC, 478 F.2d 926 (D.C. Cir. 1973); Lakewood Broadcasting Serv., Inc. v. FCC, 478 F.2d 919 (D.C. Cir. 1973); Citizens Comm. v. FCC, 436 F.2d 263 (D.C. Cir. 1970). See also Hartford Communications Comm. v. FCC, 467 F.2d 408 (D.C. Cir. 1972).

- 506 F.2d 246 (D.C. Cir. 1974) (en banc).

- Development of Policy re: Changes in the Entertainment Formats of Broadcast Stations, 60 F.C.C.2d 858 (1976) (policy statement).

10 WNCN Listeners Guild v. FCC, 610 F.2d 838 (D.C. Cir. 1979) (en banc), cert. granted, $100 \mathrm{~S}$. Ct. 1273 (1980).

1 See Part I infra.

12 See note 66 infra. 
any of these three approaches. ${ }^{13}$ The article then extends the analysis to license renewal comparative hearings. It employs axiomatic social choice theory to suggest that unless the paternalistic choice of format is found both legal and desirable, the WEFM doctrine may encourage the FCC to act illegally in its determination of the public interest and then hide the violations in deliberately murky decisions. ${ }^{14}$ The article speculates that the Commission's alternative to the WEFM doctrine-unfettered licensee choice of entertainment format-is a preferable policy because it does not induce the Commission to act unlawfully. ${ }^{15}$ Finally, this article shows that the problems with the WEFM doctrine stem from its mixture of the delegation of power to the FCC under the "public interest" standard with the reasoned decision making standard of review.

\section{The Dispute Between the D.C. Circuit and the FCC Regarding Entertainment Formats}

\section{A. WEFM}

Citizens Committee to Save WEFM v. FCC ${ }^{16}$ involved a typical fact pattern and illustrates the District of Columbia Circuit Court of Appeals' format doctrine. Starting in 1940, WEFM, a subsidiary of Zenith Radio Corporation, provided commercial-free classical music to listeners in Chicago. ${ }^{17}$ In 1966, WEFM began to include some paid commercial announcements in its broadcast material, assertedly because of increased costs. In 1972 Zenith sought to sell WEFM to GCC, a corporation formed to purchase the license. In its application for a license transfer, GCC stated that it intended to change the format from classical to "contemporary"18 music. The Citizens Committee to Save WEFM filed a petition with the FCC to deny the transfer. It claimed that WEFM served an area that received classical music from no AM stations and, in most of the service area, from only one other FM station. ${ }^{10}$ The Committee also contended that both it and the FCC had received many letters protesting the proposed sale, and that Zenith's losses

13 See Part II infra.

14 See Part III infra.

15 See Part IV infra.

16 506 F.2d 246, 252 (D.C. Cir. 1974) (en banc).

17 Zenith supported the station in order to have a proving ground for its work on FM radio receivers. Id. at 253.

18 "Contemporary" later was defined as rock. Id. at 254.

19 Zenith Radio Corp., 38 F.C.C.2d 838, 844 (1972). 
were not attributable to the classical format but occurred because Zenith had not programmed enough commercials. ${ }^{20}$ Finally, the Committee noted that Zenith had contended in its 1970 renewal application that continuation of WEFM's classical music format was in the public interest. ${ }^{21}$ On the basis of these allegations, the Committee requested that the FCC hold a hearing on whether the proposed format change would be in the public interest. ${ }^{22}$

The filings in opposition to the Committee's petition ${ }^{23}$ contended that Zenith had attempted and failed to operate WEFM on a profitmaking basis. ${ }^{24}$ They alleged that GCC had decided to change WEFM's format only after studying the needs of the listeners, and that classical music would be stronger in the Chicago area with only two competing stations rather than three. ${ }^{25}$

The FCC denied the Committee's petition, holding that no hearing was required because the abandoned format was carried by two other stations and the licensee had been suffering continuing operating losses. ${ }^{26}$ The Committee appealed to the D.C. Circuit. ${ }^{27}$

Judge McGowan, writing for the court sitting en banc, first reviewed the facts and then proceeded to sketch out the relevant statutory framework. Under section 309(a) of the Communications Act of $1934,{ }^{28}$ the FCC must grant a license application if and only if the grant would serve the public interest, convenience, and necessity. Section 309(d)(1) allows any party in interest to file a petition to deny, which must contain "specific allegations of fact sufficient to show ... that a grant of the application would be inconsistent with [the public interest]."20 Section 309(d)(2) requires the Commission to hold a hearing "[i]f a substantial and material question of fact is presented or if the Commission for any

20 Id. at 839.

21 Id.

${ }^{22}$ Hearings on matters affecting the public interest are mandated by 47 U.S.C. § 309(d) (1976) if there is any "substantial and material question of fact."

${ }^{2 s}$ These responses were made by both Zenith and GCC. Zenith Radio Corp., 38 F.C.C. $2 \mathrm{~d} 838,838$ (1972).

${ }^{24}$ This argument was made by Zenith. Id. at $840-41$.

${ }_{25}$ This argument was made by GCC. Id. at $842-43$. WNIB-FM provided classical music to all of Chicago, but reached less than one-half of WEFM's service area. 506 F.2d at 263 n.22. GCC nevertheless regarded WNIB as an alternative source of classical music. 38 F.C.C. $2 \mathrm{~d}$ at 843.

${ }^{26}$ Zenith Radio Corp., 38 F.C.C.2d 838 (1972).

27 Such appeal is authorized by 28 U.S.C. $\$ \S 2342-2343$ (1976); 47 U.S.C. $\S 402(a)$ (1976).

${ }^{28} 47$ U.S.C. $\S \S 151-609$ (1976).

20 Id. § 309(d)(1). 
reason is unable to find that grant [sic] of the application is consistent with [the public interest]."so

From prior cases, the court drew the proposition that the public has an interest in diversity of radio formats." "The disappearance of a distinctive format may deprive a significant segment of the public of the benefits of radio, at least at their first-preference level."s2 Hence, the FCC must determine if the new licensee proposes to abandon a format that is "unique or otherwise serves a specialized audience that would feel its loss."3s If so, the Commission must consider whether the public interest would be served by the format change. That determination may require the FCC to hold public hearings. ${ }^{34}$

The court also explained the relationship between the public interest standard and the uniqueness of the format to be abandoned, the format's financial viability, and listener preferences. The court indicated that "uniqueness" includes two concepts with regard to the format to be abandoned: first, it might not be duplicated in the licensee's entire service area, ${ }^{35}$ and second, it might include entertainment programming that is fundamentally different (according to a listener with rather finely discriminating taste) from any other broadcast fare. ${ }^{36}$ If the format to be abandoned is unique in either of these senses, the Commission must consider the importance of losses in listener satisfaction in determining which format best serves the public interest. ${ }^{37}$ According to the court, the public interest does not require a licensee to program a format that is not financially viable. A new licensee who seeks to abandon a unique format, however, bears the burden of showing both that the station lost money and that the losses were due to the format

${ }^{30} \mathrm{Id}$. § $309(\mathrm{~d})(2)$.

s1 $506 \mathrm{~F} .2 \mathrm{~d}$ at 259-62.

${ }^{32} I d$. at 262 .

ss $I d$.

s4 Id. The court used language paralleling the part of section 309(d)(2) quoted in text at note 30 supra to indicate when a hearing would be required. 506 F.2d at 262 .

ss This is different from its city of license. Id. at 263. "Service area" as used in this article means the area covered by any station's broadcasts. Technically, the concept is applicable only to AM radio stations, 47 C.F.R. $\$ 73.11$ (1979). For the analogous terms in other media, see, for example, id. § 73.311 (commercial FM stations); id. \$73.683 (television stations).

${ }^{38} 506$ F.2d at 264-65. The court suggested, id. at 264 n.28, that the FCC may have to distinguish between two classical music stations, one of which plays music composed before the twentieth century while the other "concentrate[s] on twentieth century works."

37 Id. at 263-65. 
rather than some other cause such as poor management. ${ }^{38}$ Finally, the court stated that listener preferences for the new and old formats help determine which best serves the public interest. The FCC may not, however, automatically select the format that is preferred by more people. Because the airwaves are communally owned, the Commission must also consider minority tastes. ${ }^{30}$

Format inquiries by the FCC are needed, according to the WEFM court, because advertiser-supported radio stations will program so as to attract the demographically desirable audience of groups with large discretionary incomes. "[B]roadcasters, left entirely to themselves by the FCC," the court feared, "would shape their programming to the tastes of [those with such incomes]."40 Such a result would clash with the public interest."1

\section{B. The FCC's Policy Statement}

In response to WEFM, the FCC issued a Notice of Inquiry'2 regarding changes in entertainment formats, and then produced a Policy Statement. ${ }^{43}$ The Policy Statement completely repudiated the WEFM format doctrine and adopted a policy of unfettered licensee choice of entertainment formats. The Commission supported the policy change with legislative history and Supreme Court precedents suggesting that the WEFM format doctrine is fundamentally subversive of the FCC's proper role in regulating broadcasters. ${ }^{44}$ The FCC also contrasted the comparative merit of

ss Id. at 261-62.

ss Id. at $260-61$.

10 Id. at 268. The court's discussion began by noting that there is no "free market in radio entertainment because over-the-air broadcasters do not deal directly with their listeners." Id. In light of the WEFM court's concern that "too many" stations would program for individuals with large discretionary incomes because of advertiser preferences, it seems odd that the court began with such a lament. The existence of a "free market" in general would do nothing to remove biases in favor of those with large discretionary incomes.

${ }^{41}$ Id. Because the court found several substantial and material issues of fact, it remanded WEFM to the FCC for further proceedings. Id. at 268. Judge Robb dissented, finding no real issue as to the abandonment of a unique format, requiring a hearing, in the case. Id. at 284-86 (Robb, J., dissenting).

42 Development of Policy re: Changes in the Entertainment Formats of Broadcast Stations, 57 F.C.C.2d 580 (1976) (notice of inquiry).

4s Development of Policy re: Changes in the Entertainment Formats of Broadcast Stations, 60 F.C.C.2d 858 (1976) (policy statement).

"The FCC argued that the Communications Act of 1934 does not make broadcasters common carriers and that imposing the WEFM doctrine on broadcasters would impose common-carrier obligations. This would be unlawful, claimed the Commission, under CBS, Inc. v. Democratic Nat'l Comm., 412 U.S. 94 (1973). Development of Policy re: Changes in the Entertainment Formats of Broadcast Stations, 60 F.C.C.2d 858, 858-61 (1976) (policy 
unrestricted format choice with the drawbacks inherent in the WEFM format doctrine. The Commission claimed that unrestricted format choice had produced a large number of different formats. Further, audience shares varied significantly between stations programming the same format in the same listening area, suggesting that listeners have strong preferences for different versions of the same format. ${ }^{45}$ The FCC contended that unrestricted format choice allows listeners to give a "rough expression of whether their preference for diversity within a given format outweighs the desire for diversity among different formats." 46 The Commission argued that although the "market allocation method" is not perfect, ${ }^{47}$ it is not beset by the serious difficulties that plague the WEFM doctrine. ${ }^{48}$ First, the broadcast of a unique rather than a duplicated format will not necessarily maximize consumer welfare. The Commission believed that to determine which format would achieve such maximization, the FCC would have to measure the intensity of listeners' preferences. Such a determination, it said, would have high administrative costs and would be slow in responding to changes in listener preferences. ${ }^{40}$ The Commission further contended that it would be impossible to define formats precisely enough to give broadcasters guidance as to what the public interest required. This inherent ambiguity would also result in a need for a hearing on any license renewal or transfer to determine whether there was any deviation from a unique format. ${ }^{50}$ The possibility of such hearings, the Commission argued, would in turn de-

statement).

4s Development of Policy re: Changes in the Entertainment Formats of Broadcast Stations, 60 F.C.C.2d 858, 863-64 (1976) (policy statement). See Appendix B, id. at 872. The FCC did not adopt the fine distinction between formats proposed by the WEFM court, see text and note at note 25 supra. Instead, it relied on the broadcast industry's own relatively broad categories, such as "classical" and "rock." See id. at 862, 875-78.

46 Id. at 863 (emphasis in original).

47 Id.

18 The FCC's selection of unfettered licensee choice of radio formats stands on the correct and often overlooked principle that administrative regulation is not always the preferable alternative, even when market performance is less than perfect.

What is the "bottom line" on non-market [regulatory] failure? Like that of market failure, it must be entered in red ink, although its numerical sum is unclear. Whether the red-ink entry for the one is greater or less than that for the other can't be answered in general terms. Sometimes one may be greater, sometimes the other. The answer will depend on the specifics of particular cases.

Wolf, A Theory of Non-Market Failures, 55 The Public Intzrest 114, 132-33 (1979).

40 60 F.C.C. 2 d at $863-65$.

so Id. at $862-63$. 
ter innovative programming. ${ }^{31}$ Finally, the FCC asserted that the WEFM doctrine would be very expensive. The Commission claimed that the format abandonment hearings required by $W E F M$ are inherently complex and costly, ${ }^{\mathrm{b2}}$ and that because the WEFM doctrine would require the FCC to hold hearings on license renewals as well as on license transfers, ${ }^{\text {ss }}$ such hearings would occur frequently.

\section{WNCN}

The District of Columbia Circuit Court of Appeals, sitting en banc, invalidated the FCC's Policy Statement in WNCN Listeners Guild v. FCC. ${ }^{\text {s4 }}$ Judge McGowan, again writing for the majority, reiterated the WEFM doctrine: "[w] here a significant sector of the listening community, in opposition to the assignment, protests the loss of a [distinctive programming] format by substantial factual allegations that it is both unique and financially viable, the statute requires that the Commission hold a hearing." the Policy Statement, the majority proceeded to respond to the Commission's contentions. ${ }^{.6}$ The court claimed that the aggregate costs associated with format hearings are not likely to be large. Few format cases ever arise, and most of those that do either do not require a hearing or are settled before one is held. Further, even though hearings may be required in some renewal cases, the total number of hearings will still be low because of the safeguards built into the WEFM doctrine. ${ }^{57}$ The majority suggested that the FCC had refused to implement the WEFM doctrine in such a way "as to minimize [its] drawbacks while preserving [its] essence."

s2 Id. at 865 .

${ }^{82}$ Id. at 864-65. This expense was especially troubling to the FCC because it viewed the results of such hearings as essentially speculative. $I d$. at 865 . This is particularly true of the WEFM mandate to determine whether a format could have been financially viable. Id. at 863 n.5.

is Id. at $862-63$.

st 610 F.2d 838 (D.C. Cir. 1979) (en banc), cert. granted, 100 S. Ct. 1273 (1980).

Bs Id. at 841 .

s8 Id. at 843-58. A significant portion of the majority's opinion, id. at 846-47, reviewed the propriety of the Commission's behavior regarding Appendix B to the Policy Statement, 60 F.C.C.2d at $872-81$. This article will not address the legality of the FCC's behavior on this point.

8: 610 F.2d at 848-49. The safeguards are the need to prove both that the format is unique and financially viable and that there has been a sufficient degree of protest by the public.

ss Id. at 852. 
The court held that the FCC should develop a taxonomy of formats or, alternatively, do away altogether with the concept of a format and concentrate, instead, on listener dissatisfaction. ${ }^{\text {b9 }}$ In this vein, the court virtually invited the FCC to protect licensees from the WEFM doctrine by requiring petitioners to satisfy very exacting criteria before a hearing would be held. ${ }^{60}$ Further, the court suggested that the FCC remedy the tendency of the WEFM doctrine to discourage innovative programming by exempting from the hearing requirements experimental formats abandoned shortly after adoption. ${ }^{81}$ Finally, the court deemed irrelevant the FCC's contention that the market generally does a good job of allocating formats, because the WEFM doctrine is only applicable to the rare cases of market failure. ${ }^{22}$

The court then stated its view of the proper relationship between the FCC and the courts. The court must explain the legal constraints on the Commission's activities. The WEFM doctrine represents the court's controlling interpretation of the applicable laws, rather than merely a suggested policy. Therefore, the FCC must enforce the doctrine in good faith. Based on this understanding of its role, the court voided the Policy Statement.

Judge Tamm dissented, emphasizing the majority's willingness to allocate a broadcast license so that a minority group of listeners might listen to their unique-format first choice while a second, larger group of listeners had to settle for their second choice because their preferred format was duplicated. ${ }^{64}$ This approach only

so Id. at 853 \& n.47.

1 Id. at 854. Among the criteria suggested by the court are the existence of many public complaints and a demonstration by petitioners of the format's uniqueness. The court also indicated that the FCC could use broad categories of formats, thus reducing the number that would be found to be unique. This constitutes an implicit retreat from the full rigors of WEFM. See text and note at note 36 supra.

i 610 F.2d at 854. To the extent that the D.C. Circuit would later follow these dicta and allow the Commission to place the burden of showing uniqueness on petitioners, to classify formats into broad categories, and to exempt experimental formats from hearing requirements, license transfer proceedings would be less troubled by the WEFM doctrine. Regardless of the D.C. Circuit's attitude towards these procedures, however, the WEFM doctrine still will cause grave problems for broadcast license comparative hearings. See Part III infra.

es Id. at 856 .

es Id. at 854-58. For a forceful argument that WEFM (and, by an extension of reasoning, the voiding of the Policy Statement) stands on an unjustifiable and unwise notion of judicial review of administrative action, see Polsby, FCC v. National Citizens Committee for Broadcasting and the Judicious Uses of Administrative Discretion, 1978 SUP. CT. REv. 1.

- Judge Tamm thought that this holding departed from the enunciation of the format 
makes sense, the dissent asserted, if the FCC can distinguish between unique and duplicated formats and measure the intensity of listener preferences. The dissent doubted the workability of the "unique format" concepi and believed that "it is either impossible or extremely difficult to compare the intensity of preferences of different persons." "Bs Finally, Judge Tamm noted that even if the FCC were able to collect such data, there is no clear way to combine the information so as to discover the public interest. Because of these considerations supporting the FCC's Policy Statement, Judge Tamm would have upheld the Commission.

\section{A Social Choice Theoretical Analysis of the WEFM DOCTRINE}

This article will now use axiomatic social choice theory ${ }^{86}$ to provide a complete taxonomy of the substantive options in determining which of two alternative formats best serves the public interest. This taxonomy will help both to explain why unfettered licensee choice of format is preferred by the FCC, and to suggest extreme caution in accepting the WEFM doctrine until its actual consequences are perceived and evaluated.

\section{A. Assumptions}

The following assumptions are made for purposes of the analy-

doctrine in WEFM, 610 F.2d at 860-64 (Tamm, J., dissenting), but I find no substantial difference between the majority opinion reversing the Policy Statement and WEFM.

ss Id. at 863 (Tamm, J., dissenting).

68 Axiomatic social choice theory concerns the investigation of problems in society's choice of one rule, policy, or state of the world out of a number of rules, policies, or states of the world by positing a set of axioms (or assumptions) about the operation of the choosing mechanism and then deducing conclusions from this set of assumptions. For example, one relatively bland axiom about such choices states that if society is choosing between options $X$ and $Y$, and all the citizens prefer $X$ to $Y$, then $Y$ should not be chosen. For a general introduction to this subject, see Plott, Axiomatic Social Choice Theory: An Overview and Interpretation, 20 AM. J. PoL. ScI. 511 (1976). The D.C. Circuit's handling of the WEFM doctrine may be analyzed and attacked in other ways, of course. For example, the court's refusal to accept the FCC's selection of unfettered licensee choice might conflict with the institutional paradigm of an expert administrative agency formulating the best technical rules for its industry. See J. Freedman, Crises and Legitimacy: The Administrative Process and American Government 381-89 (1978); L. Jaffe, Judicial Control of AdministraTIVE ACTION 576-85 (1965). This is a particularly appropriate way to respond to WNCN, as the court explicitly rejected the FCC's expert determination that the WEFM doctrine was impracticable. A discussion of this issue, however, would require a taxonomy and evaluation of competing theories of the role of "expertise" in shaping and justifying administrative action. Such a general inquiry lies beyond the scope of this article. 
sis. First, the FCC faces a typical WEFM format change hearing: it must determine which of two programming formats would better serve the public interest. ${ }^{.7}$ Second, each listener in the service area has exactly one of the following preferences: he prefers the old format to the new one, he prefers the new format to the old, or he is indifferent ${ }^{68}$ between them. (A complete description of all listeners' preferences will be called a "preference profile.") Third, the public interest is a function of the tastes and preferences of the listening public. ${ }^{69}$

or When the FCC chooses one alternative to serve the public interest from a set of possibilities, it must, in general, choose the alternative that will best serve the public interest. This is clearly the law in the format context under 47 U.S.C. $\$ \S 307-310$ (1976). For a discussion of this principle, see Spitzer, Multicriteria Choice Processes: An Application of Public Choice Theory to Bakke, the FCC, and the Courts, 88 YALE L.J. 717, 739, 741-42 (1979). This article therefore uses the notions of FCC choice and a format better serving the public interest interchangeably in the text.

os Indifferent listeners include both people who would listen to each format one half of the time if they were offered simultaneously and people who would not listen to either format.

6o This assumption is shared by both the D.C. Circuit, see, e.g., WNCN Listeners Guild v. FCC, 610 F.2d 838, 857 (D.C. Cir. 1979) (en banc), cert. granted, 100 S. Ct. 1273 (1980); Citizens Comm. v. FCC, 463 F.2d 263, 272 n.7 (D.C. Cir. 1970), and the FCC itself, see Development of Policy re: Changes in the Entertainment Formats of Broadcast Stations, 60 F.C.C.2d 858, 863-64 (1976) (policy statement).

Alternatively, one might contend that there is an individual "right" to hear a favorite viable format on the radio. Such a right might be implied by a dictum in Red Lion Broadcasting Co. v. FCC, 395 U.S. 367 (1969). The Supreme Court stated: "It is the right of the public to receive suitable access to social, political, esthetic, moral, and other ideas and experiences which is crucial here. That right may not constitutionally be abridged either by Congress or by the FCC." Id. at 390 . Some commentators have argued that this language supports an affirmative right to hear discussion of public issues and controversial topics. See J. BArron, Freedom of the Press for Whom? The Right of Access to Mass Media 144-49 (1973). But this quotation does not necessarily import an individual right. Note, The Listener's Right to Hear in Broadcasting, 22 STAN. L. REv. 863 (1970), argues that although the quoted language might support an individual right to hear, it more likely indicates that the public's right to hear must be included in some larger, overall public interest calculus. Id. at 874-75. In addition, CBS, Inc. v. Democratic Nat'l Comm., 412 U.S. 94 (1973), which denied the Democratic National Committee a right of access to network time for presenting political messages, undermines the philosophical foundations of the quoted language.

Assuming that the Red Lion language is still viable regarding public issues and that it defines individual rather than group rights, one would still have to argue that such rights carry over into entertainment programming; the portion of the quoted language that included aesthetics was clearly dictum.

Even if one could overcome these initial hurdles to show that there is an individual right, in general, to entertainment programming in the broadcast media, it is extremely unlikely that such a right would extend to the radio format situation. In dealing with a public forum, practical considerations may determine whether a first amendment right exists. Lehman v. City of Shaker Heights, 418 U.S. 298, 302-03 (1973) (plurality opinion) ("the nature of the forum and the conflicting interests involved have remained important in determining the degree of protection afforded by the First Amendment to the speech in question"). 


\section{B. Axioms}

Next, consider each of the following axioms about the nature of the choosing process. ${ }^{70}$ These axioms may represent legal rules regarding behavior by the FCC. ${ }^{11}$ That is, the courts might constrain the FCC to determine the public interest in accordance with one or more of the axions. Alternatively, the axioms may represent physical or practical constraints on the Commission's choice process. For example, the FCC maintains that it cannot practicably use data on intensities of listeners' preferences to determine the public interest. Finally, the axioms may stand for values or principles of a fair or just choosing process.

1. Axiom 1: Listeners are fungible. ${ }^{72}$ The personal identities of the listeners who have preferences will not affect the choice of a

Several practical problems preclude granting an individual right to hear a favorite, viable format. First, there are likely to be more such formats than there are channels available. The WEFM doctrine is concerned with service to listeners in a station's service area, rather than its city of license. See text and note at note 35 supra. Because two stations' service areas are not likely to coincide, it is correspondingly unlikely that any two stations can be considered substitutes for one another. This situation is exacerbated to the extent the D.C. Circuit enforces WEFM's call for fine discrimination between formats rather than WNCN's suggestion of a broad taxonomy. See text and notes at notes 41, 60 supra. If there are more viable formats than channels, then some listeners must be denied their "rights" in the name of other listeners' "rights." The decision to grant one of two identical demands on a resource seldom characterizes the protection of individual rights. Indeed, individual rights usually are opposed by more diffuse societal interests which are different in nature from those of the individual. Because the D.C. Circuit has ruled out using any numerical minima to determine the size of the group to which an individual must belong before he has an interest in entertainment programming, see Citizens Comm. to Keep Progressive Rock v. FCC, 478 F.2d 926, 929 n.7 (D.C. Cir. 1973), and outright discrimination in granting these rights on the basis of membership in racial or ethnic groups is probably not constitutional, this situation would seem intolerable.

Further, extending individual rights to hear favorite formats will cause difficulties regardless of whether there are more viable formats than channels. It will be difficult to justify an individual-rights approach to listeners who are not favored in any particular case. The losing listeners who preferred a duplicative format must be persuaded that preferences between different formats are so much more important than preferences between different variations of the same format that the latter preferences do not even count in determining the public interest. Also, entertainment programming does not seem as important as other subjects, such as freedom from unreasonable search and seizure, to which absolute, individual rights attach.

In sum, it is extremely unlikely that the public interest in radio formats resides in individual rights to favorite formats.

70 The axioms and the theorems drawn from them are taken from P. Fishiurn, ThE Theory of Social Choice 1-69 (1973).

${ }^{71}$ For a discussion of the various sources of legal constraints on the FCC's behavior, and a discussion of the philosophy of axiomatizing such constraints, see Spitzer, supra note 67 , at 736-38.

72 Axiom 1 corresponds to Definition 5.3 in P. FishBuRn, supra note 70, at 55. 
format to serve the public interest best. Therefore, if any two listeners exchange preferences, the choice of format does not change. For example, if A preferred the old format to the new and B were indifferent, and both A and B shifted to the other's preference so that $A$ was indifferent and B preferred the old format, then the shift would not affect the FCC's choice. Such a choice process necessarily depends only on the number of listeners who prefer one format to another or are indifferent between the two. ${ }^{73}$

The D.C. Circuit's opinions give no hint as to whether Axiom 1 must characterize the FCC's determination of the public interest, except insofar as they preclude majority rule. As the analysis below reveals, however, Axiom 1 clearly is both a practical constraint on the FCC's decision making and an approximation of notions of equality and fairness in decision making.

In the license transfer context, Axiom 1 might be violated ethically ${ }^{74}$ in two ways. The FCC could weigh certain listeners' views more heavily because of their membership in certain minority groups based on, say, ethnic background, ${ }^{75}$ or it could attempt to use intensity of preference information. There is no suggestion in any of the format cases or in the Policy Statement that WEFM hearings should be used to aid any disadvantaged minority groups. In the context of initial broadcast license comparative hearings, the FCC, under direction from the courts, ${ }^{76}$ has granted a "merit" to those applicant stations of which a significant proportion is owned by ethnic or racial minorities. An attempt to import this approach into WEFM format hearings, however, might encounter problems. First, because selection of format is more directly related to control of content than is selection of a licensee, evaluation of format may be more sensitive in terms of first amendment values than evaluation of stock ownership. Second, the courts

7s This axiom is widely applicable. For instance, in the reapportionment context a version of Axiom 1 probably represents a constraint on states' prerogatives in drawing legislative boundaries. See, e.g., Hadley v. Junior College Dist., 397 U.S. 50 (1970) (states must ensure elections in which each person's vote is equally weighed, insofar as possible).

7t I am not considering such phenomena as graft, bribery, friendships, or political influence, all of which would improperly increase the weight of certain listeners' views, nor animosities or prejudices, which would impermissibly decrease the weight of some listeners' preferences.

7s But cf. Regents of the Univ. of Cal. v. Bakke, 438 U.S. 265 (1978) (preferring members of any one group for no reason other than race or ethnic origin is constitutionally forbidden discrimination).

7e WEVP v. FCC, 513 F.2d 1056, 1062 n.40 (D.C. Cir. 1975); TV9, Inc. v. FCC, 495 F.2d 929, 938 (D.C. Cir. 1973), cert. denied, 419 U.S. 986 (1974). 
might conclude that initial broadcast license comparative hearings need such a bias far more than WEFM hearings do. Whereas it is demonstrable that minority ownership of broadcast facilities is abysmally low, ${ }^{77}$ minorities may satisfy entertainment desires through many alternatives to the contested station, such as other broadcasters, motion pictures, records, and tapes. Finally, while ownership by individuals from a minority group is easily provable, demonstrating preference for a format by a minority group as a group would be much more difficult. These arguments are not meant to prove that the FCC may not, as a deliberate policy, weigh the preferences of members of certain ethnic, racial, or religious groups more heavily. Instead, they are intended to show that there are serious doubts as to the wisdom and legality of doing so that have not yet been considered by the FCC or the courts.

The FCC could also attempt to avoid Axiom 1 by incorporating intensity of preference information into the choice, ${ }^{78}$ but this would be impractical. The D.C. Circuit created the WEFM doctrine because advertiser-supported programming caters to the preferences of individuals who have large discretionary incomes.70 Assuming that listeners prefer one format to another with varying intensities of feeling, ${ }^{80}$ one possible measure of these intensities of preference consists of a listener's willingness to pay money directly for radio entertainment. ${ }^{81}$ Unfortunately, this measure is also biased in favor of those with large discretionary incomes. In general, people with large incomes will be willing to pay more for radio entertainment, just as they are more likely to patronize products that advertisers wish to sell. There would be no way to distinguish individuals with very intense preferences from those with large disposable incomes.

The FCC could, of course, attempt to gather wealth-neutral

${ }^{77}$ As of March 1980, minority group members owned only $1.4 \%$ of the broadcast stations in the country. Federal Communications Comm'n, Public Notice: Broadcast Station TOTALS FOR MARCH 1980 (1980).

${ }^{28}$ P. FrshbuRn, supra note 70, at 9-10, notes that this approach intentionally excludes intensity information. For a general discussion of the relationship of the theory of social choice to intensity of preference, see A. Sen, Collective Choice and Social Welpare 89131 (1970).

${ }^{70}$ Citizens Comm. to Save WEFM v. FCC, 506 F.2d 246, 268 (D.C. Cir. 1974) (en banc).

${ }^{\text {so }}$ Not all commentators are willing to concede this much. See, e.g., Plott, supra note 66 , at 541 .

81 Brenner, Government Regulation of Radio Format Changes, 127 U. PA. L. REv. 56, $85-86$ (1978). Such willingness could be measured by subscription sale financing. Id. at 8687. 
data directly. For instance, it could ask listeners how strongly they prefer one format over another. As Judge Tamm pointed out, however, until both formats are broadcast, the listeners may have no idea what the new format would be like. ${ }^{82}$ They would therefore lack sufficient information to answer the question. Even if this objection is set to one side, several problems remain. Without an observable bidding or other market-like procedure, the FCC will have no way of ascertaining the accuracy of the responses. Listeners would have every incentive to misrepresent intentionally their feelings to the Commission if they thought that their favorite format would be more likely to be chosen should the FCC believe that preferences for that format were strong. Even if the FCC surmounted these problems, it would still have to expend significant resources to gather necessary information. Acquiring reliable data on the intensity of listeners' preferences would require questioning at least a representative sample of listeners about such preferences. This might cost so much money that the FCC could not shoulder the burden.

Finally, even if the FCC were able to collect reliable information on intensities of listener preferences, there is no obvious sense in comparing different listeners' intensities of preferences and no clear way to use the information to make a choice. ${ }^{83}$ As Judge Tamm noted:

The majority's "substitution" theory assumes that the Commission will be able to balance number of listeners against intensity of format preference. Consider the top 40/ classical format hypothetical. If twenty percent of the listening audience would mildly prefer a second top 40 format and five percent would vigorously prefer a retention of the classical format, does the size of one audience outweigh the intensity of preference of the other? The majority opinion offers no clue. ${ }^{84}$

Such a determination, moreover, would require the FCC to decide that the preferences of one group are felt more deeply than those of the second group. In the event that the two groups divided

${ }^{82}$ WNCN Listeners Guild v. FCC, 610 F.2d 838, 863 (D.C. Cir. 1979) (en banc) (Tamm, J., dissenting), cert. granted, 100 S. Ct. 1273 (1980).

ss See Plott, supra note 66, at 541-42. At the same time, I refrain from stating that there clearly is no method for using cardinal-intensity-of-preference data to make a choice. I make only the point that any attempt to utilize such data will have at least some difficulties.

st 610 F.2d at 863-64 (Tamm, J., dissenting). 
along racial or ethnic lines, ${ }^{85}$ such findings could be highly distressing both politically and emotionally. This discussion shows that as a practical matter, plans to use intensity of preference information to choose a format are quite likely to fail. Even the most commonly suggested, obvious approaches must overcome significant barriers to their successful implementation.

In sum, Axiom 1-that listeners are fungible-represents a principle for choosing one of two radio formats that may be violated either by attaching more importance to the preferences of members of certain groups or by use of data on intensity of listener preference in the choice of a format. Although either approach conceivably could be workable, each has serious problems which tend to render it unacceptable.

2. Axiom 2: Formats are fungible. ${ }^{83}$ The explanation of this axiom begins with the supposition that the choice between formats is based on a preference profile. This means that if all the listeners should reverse their preferences, then the FCC's choice would be reversed. In other words, if the FCC were to determine that the old format best served the public interest, and then all those favoring the old format were to switch to the new format, while all those formerly favoring the new format were to switch to the old, then the FCC would have to conclude that the new format best served the public interest. ${ }^{87}$

Axiom 2-which guarantees that alternative formats will be treated equally -is best investigated by exploring three obvious methods of violating it. The FCC could violate Axiom 2 by using data on the intensity of listeners' preferences, adopting a paternalistic attitude toward certain formats, or using a strong presumption for the status quo. The remarks concerning the use of data on intensity of listeners' preferences in the discussion of Axiom 1 need not be repeated. Again, the idea is impractical.

Paternalism is an approach that regards one format as preferable to a second, irrespective of listeners' desires, because it is a "merit good": it is thought to be better for listeners regardless of their preferences. Paternalistic format allocation has not been given serious consideration by either the D.C. Circuit or the FCC.

ss For an example of such a situation, see WDAI Doesn't Think It's Disco, Shifts to the Adult-Rock Route, Chi. Tribune, May 7, 1980, § 3, at 14 (story of a station's format change so as to leave behind an audience "heavily skewed toward Black and Latino listeners").

${ }^{88}$ Axiom 2 corresponds to Definition 3.1 in P. Fishburn, supra note 70, at 26.

87 This assumes that the formerly indifferent did not develop preferences. 
Indeed, the court appeared to recognize an antipaternalistic philosophy in the Communications Act itself when it observed that "one man's Bread is the next man's Bach, Bacharach, or Buck Owens and the Buckaroos, and ... . it is in the public's best interest to have all segments represented."

This philosophy would appear entirely sound. Although public affairs and educational programming have often been accorded merit-good status, ${ }^{89}$ granting such status to entertainment formats might have grave implications for both the first amendment and the anticensorship provision of the Communications Act. ${ }^{80}$ Choosing formats would require the FCC to grant merit-good status on paternalistic grounds to some formats and not to others, requiring the government to discriminate between alternative expressions merely because the government likes or approves of certain contents. This would seem to threaten first amendment values. ${ }^{91}$

ss Citizens Comm. to Keep Progressive Rock v. FCC, 478 F.2d 926, 929 (D.C. Cir. 1973).

so Brenner, supra note 81 , at 90.

- 47 U.S.C. $\$ 326$ (1976) forbids censorship by the FCC. For a concise explanation of these censorship problems, and an attempt to sidestep them, see Brenner, supra note 81 , at $90-92$.

"1 The merit-goods approach has been endorsed recently by Brenner, supra note 81 , but I remain unconvinced. Brenner argues for such a policy on the basis of the following hypothetical:

Following a Christmas Eve earthquake, officials determine that a warning to homeowners in a remote town to disconnect gas mains could avoid $\$ 250,000$ in aggregate property damage. The only practical way to disseminate this warning is by transistor radio. However, a religious music fanatic is willing to pay $\$ 275,000$ to all radio stations in the quake area in order to enjoy twenty-four hours of uninterrupted holiday music. If a preference intensity approach to program purchasing is assumed, the value of uninterrupted musical programming exceeds the value to property owners of that air time. In terms of economic efficiency, the sole bidder should not be denied his uninterrupted programming. Yet the compulsion to program inefficiently is strong.

Id. at 91. Brenner justifies the "compulsion to program inefficiently" on two grounds. First, property owners who suffer "avoidable loss because a single listener has satisfied his desires" are disappointed. Second, "there is the loss felt by the community because a resource that should be marshalled to serve a broad public purpose is squandered to satisfy the musical appetite of an individual listener." Id. at 92 . He then proposes that "the resulting community disappointment provides by consensus a reasonable ground for applying a merit goods approach." Id. Finally, Brenner stretches his proposition to provide support for a merit goods approach to entertainment formats.

It is difficult to see the logical connection between the hypothetical, with its two "justifications," and the subsequent proposition as applied to entertainment formats. First, Brenner's hypothetical deals with a choice between using the frequency either to avert widespread property damage or to provide entertainment. This is a fundamentally different problem from that of choosing one of several alternative entertainment formats. Whereas one might be tempted to label avoidance of property loss a merit good when it is compared with entertainment, I am mystified as to why one would wish to call one (and only one) of two entertainment formats a merit good. Brenner leaves unexplained the relationship be- 
Another possible violation of Axiom 2 would be to accord a preference to the status quo, the old format, simply because it is the status quo. Neither the D.C. Circuit nor the FCC has considered this approach. In the context of broadcast license renewal hearings, the FCC's preference for renewal applicants over challengers, merely because the renewal applicants represent the status quo, has met with an unfriendly reception in the courts. ${ }^{22}$ It might be argued that in a WEFM license transfer hearing the old format should have an advantage because listeners who have been accustomed to hearing their preferred format will feel the loss more acutely than those listeners who have never heard their as yet unbroadcast preferred format. This argument is defective. It is based ultimately on notions of intensity of preference. Therefore, the preference for the status quo should be outweighed by a sufficiently intense preference for the new format. But such comparison is subject to the analysis on this point in the discussion of Axiom 1. Further, an attempt to use this principle may lead to some puzzling results. Both the D.C. Circuit ${ }^{93}$ and the FCC ${ }^{94}$ agree that, under WEFM, if a licensee abandons a unique and viable format during his term of license and a substantial number of people protest the change, the FCC must hold a format hearing at license renewal time. At that time, the new format may have been broadcast for a period of time ranging between a few days and three years. ${ }^{95}$ If the new format has been broadcast for only a short time, an argument based on listeners' habits still suggests a bias in favor of the old format. Conversely, if the "new" format has been in place for years, then perhaps a bias in favor of that format would be appropriate. Thus, if the Commission is to avoid arbitrary line-

tween the favored entertainment format and a "broad public purpose." Indeed, in his conclusion, Brenner admits that his plan "summons the FCC to intrude into programming operations of stations with little more than its intuition about merit goods as a guide." Id. at 110.

Second, Brenner's hypothetical concerns a conflict between the entire community and one individual. Although such a conflict is quite interesting theoretically, it seems to have little relevance to the WEFM situation, which generally pits small groups against each other.

${ }^{92}$ See note 125 infra.

93 WNCN Listeners Guild v. FCC, 610 F.2d 838, 863 (D.C. Cir. 1979) (en banc), cert. granted, $100 \mathrm{~S}$. Ct. 1273 (1980).

2 Development of Policy re: Changes in the Entertainment Formats of Broadcast Stations, 60 F.C.C.2d 858, 861-62 (1976) (policy statement).

9s This could happen if the format change were made immediately after the grant or renewal of a license, because the maximum duration of a license is three years. 47 U.S.C. § 307(d) (1976). 
drawing, it will be forced to attempt to collect and use data on intensity of listener preference. The same problems are present in license transfer hearings, because the current licensee could change formats before consummating the transfer, so as to shift the bias to the new format. Such problems strongly suggest that treating formats unequally on the basis of a preference for the status quo may be administratively unworkable.

Axiom 2A: If the number of people preferring the old format does not equal the number of people preferring the new format, then formats are fungible. Axiom 2A is implied by Axiom 2. The analyses of Axioms 2 and 2A are almost identical. The only difference is that where equal numbers of people prefer the old and new formats, Axiom 2A says nothing about the choice function. Hence, less is needed to justify it than is needed for Axiom 2. Axiom 2A is necessary only if one simultaneously clings to Axiom 1 and denies that it is possible for the public interest to be in equipoise, even if the number of people who prefer the new format equals the number who prefer the old.8 Assume that two formats tie as to the numbers of people preferring them but that the FCC, believing that the public interest cannot be in equipoise, has determined that the new format will better serve the public interest. If everyone's preference reverses, and hence a tie is maintained, Axiom 2 would require the FCC to find now that the old format will better serve the public interest. Axiom 2 would, therefore, rule out tiebreaker rules such as "all ties will be decided in favor of the status quo." If the public interest is not allowed to be in equipoise, then such tie-breaker rules are necessary. If so, it is wise to refrain from stating anything about ties. Axiom 2A has precisely this character, and therefore allows tie-breaker rules. In particular, the Commission could resolve all ties in favor of the status quo, thereby failing to treat the formats entirely equally. Unfortunately, Axiom 2A offers the FCC no help in reaching the difficult decision of which format should be regarded as the status quo in renewal hearings.

3. Axiom 3: No listener's desires count negatively in the choice of format. ${ }^{97}$ Assume that for some preference profile, D, the FCC has made a choice between two formats. If any person then changes his preference in the direction of the chosen format, and no one else changes his preference, thereby creating preference profile $D^{\prime}$, then the choice does not change in the direction of the

* See discussion of Axiom 5 in text at notes 103-104 infra.

97 Axiom 3 corresponds to Definition 2.1 in P. Fishrurn, supra note 70, at 21. 
other format. Thus, if the first format better served the public interest given preference profile $D$, then the second format will not better serve the public interest with preference profile $D^{\prime}$, nor will the public interest be thrown into equipoise. Similarly, if the public interest was in equipoise under $\mathrm{D}$, then the second format will not better serve the public interest under $D^{\prime}$.

Axiom 3 declares that there is no person such that the public interest is served by denying him his desires. The principle rules out allowing personal or political vendettas or racial or ethnic prejudices to affect the choosing process. Although nothing in any of the format cases addresses these considerations, it seems likely that if the FCC ever admitted that such motivations affected its decision, the courts would reverse the decision as a violation of equal protection guarantees included in the fourteenth amendment. ${ }^{88}$ Hence, Axiom 3 probably represents a legal constraint on the FCC's choice process.

4. Axiom 4: The choice process is always sensitive to each listener's desires. ${ }^{99}$ If, with any given preference profile, the public interest is in equipoise between two formats, and then one person changes his mind in favor of one of the formats, ${ }^{100}$ then that newly favored format is chosen.

Axiom 4 may represent a legal constraint on the FCC's decision process. The courts have held that the FCC must accord some weight to any relevant evidence. ${ }^{101}$ If the public interest were in equipoise, and one person then changed his preference but the FCC refused to change its public interest determination, perhaps the listener could claim that the FCC was giving his preference no weight, in violation of the rule.

Axiom 4 prevents choice of format by a representative system, such as in the following example. Suppose the FCC divides listen-

- Simon, Racially Prejudiced Governmental Action: A Motivation Theory of the Constitutional Ban Against Racial Discrimination, 15 SAN DIEgo L. REv. 1041 (1978). See, e.g., Department of Agriculture v. Moreno, 413 U.S. 528, 534 (1973) (desire to harm politically unpopular group cannot constitute legitimate governmental interest such as will sustain legislative classification against equal protection challenge). $C f$. Washington v. Davis, 426 U.S. 229,239 (1976) (central purpose of equal protection clause of fourteenth amendment is prevention of official conduct discriminating on the basis of race).

90 Axiom 4 corresponds to Definition 2.3 in P. FishBuRN, supra note 70, at 24.

100 A listener may change his mind in favor of the new format by moving, for example, from a preference for the old to a preference for the new, from a preference for the old to indifference, or from indifference to a preference for the new.

${ }_{102}$ TV9, Inc. v. FCC, 495 F.2d 929, 936-38 (D.C. Cir. 1973), cert. denied, 419 U.S. 986 (1974). 
ers into four groups: Blacks, Latinos, Caucasians, and Orientals. It then announces that it will determine which of two formats, Progressive Rock or Golden Oldies, is preferred by a majority of listeners within each group and choose the format that is preferred by a majority of groups. Assume that a majority of both Blacks and Orientals prefer Progressive Rock, while a majority of Latinos and Caucasians prefer Golden Oldies. The public interest would then, according to this system, be in equipoise. Next, assume that an Oriental listener who used to prefer Golden Oldies changes his preference to Progressive Rock. Under this system the public interest remains in equipoise because the changed individual preference did not change the number of groups preferring either format.

Such a process seems institutionally odd. The tendency on the part of advertiser-supported radio to overweight the preferences of certain listeners was what prompted creation of the WEFM doctrine. ${ }^{102}$ If the groups used to make a choice in a representative system do not have equal numbers of members, then the choice process will tend to weight the preferences of those listeners in the smallest groups more heavily, contrary to the spirit of WEFM.

5. Axiom 5: The FCC must choose exactly one format. ${ }^{103}$ This axiom precludes the FCC from determining that the public interest is in equipoise. The rule rests on the notion that as long as two formats differ, the FCC should evaluate each in terms of the listeners' needs and desires and, by applying its expertise, determine which would better serve the public interest. As such, it probably constitutes a legal constraint. Although none of the format cases speaks directly to this issue, the D.C. Circuit has required the FCC to choose the one license applicant that would "better" serve the public interest ${ }^{104}$ in initial broadcast license comparative hearings. It would be inexplicable if the court suddenly were to allow the FCC to conclude in format hearings that it could not decide that either format would better serve the public interest.

\section{Theorems}

This section uses theorems from Peter Fishburn's The Theory

102 See text and notes at notes 40-41 supra.

${ }^{103}$ Axiom 5 corresponds to Definition 6.1 in P. Fishburn, supra note 70, at 62 .

${ }_{106}$ Johnston Broadcasting Co. v. FCC, 175 F.2d 351, 356 (D.C. Cir. 1949). This assumes that the applicants refuse to share time on the station. For a discussion of the requirement of choosing only one applicant, see Spitzer, supra note 67, at 739. 
of Social Choice ${ }^{105}$ to combine the axioms and deduce results. In combination these axioms ${ }^{108}$ define a majority rule choice process-that is, any process that satisfies Axioms 1, 2, 3, and 4 or Axioms 1, 2A, 3, and 5 chooses the alternative that is preferred by more listeners. These deductions will help to explain the FCC's reluctance to follow the WEFM doctrine and suggest that, as a matter of policy, the FCC's Policy Statement might be preferable to the WEFM doctrine.

Theorem 1: The FCC's choice of format can satisfy Axioms 1, 2,3 , and 4 if and only if the choice process operates as simple majority rule. ${ }^{102}$ If the FCC uses a choice process that is based on listener preferences, that regards both listeners and formats as fungible, that does not count any listener's desires negatively, and that is always sensitive to each listener's desires, then the choice process is simple majority rule ${ }^{108}$ and no other. If an equal number

105 P. Fishburn, supra note 70.

108 Technically, one must also assume that the FCC must choose the format that best serves the public interest, see text and note at note 67 supra.

${ }^{107}$ Theorem 1 corresponds to Theorem 5.4 in P. FishruRn, supra note 70, at 57.

The following discussion illustrates, in nonmathematical terms, why Axioms 1, 2, 3, and 4 combine to produce majority rule. For a mathematical exposition, see P. FisHBuRN, supra note 70, at 57-59. Axiom 1 clearly allows the FCC to rely only on numbers of listeners who hold preferences. First, assume that the numbers of listeners who prefer format $X$ and format $\mathrm{Y}$ are equal. If, in this situation, the $\mathrm{FCC}$ were to choose only format $\mathrm{X}$, and everyone then reversed his preference, Axiom 2 would require the FCC to choose only Y. The same numbers of listeners would still prefer each format, however, so Axiom 1 would require that $\mathrm{X}$ still be chosen. The only way out of this dilemma is for the FCC to "choose" both X and $\mathrm{Y}$ whenever equal numbers of listeners prefer each format.

Now assume that different numbers of listeners prefer each format. Assume, without loss of generality, that $a$ listeners prefer $\mathrm{X}$ and $b$ listeners prefer $\mathrm{Y}$ and that $a$ is less than $b$. We have already deduced that if $a$ listeners prefer $X$ and $a$ listeners prefer $Y$ then the public interest is in equipoise and the Commission chooses both $\mathrm{X}$ and $\mathrm{Y}$. Now, assuming that at least one indifferent listener (at least $b-a$ listeners are assumed to be indifferent) changes his mind to prefer $\mathrm{Y}$, so that $a$ listeners prefer $\mathrm{X}$ and $a+1$ listeners prefer $\mathrm{Y}$, then Axioms 4 and 3 require the FCC to choose Y. If, one by one, $b-a-1$ additional indifferent listeners change to preferring $\mathrm{Y}$, then Axiom 3 will continue requiring the $\mathrm{FCC}$ to choose $\mathrm{Y}$. Hence, we have shown that if more listeners prefer one format, and Axioms 1-4 are valid, the FCC must choose that format. This completes the proof.

It should be noted that neither Theorem 1 nor Theorem 2, infra, uses all six axioms. This does not mean that the omitted axioms are untrue, but merely that they are unnecessary to the theorem. It is thus possible to disagree with one of Axioms 2, 4, and 5 and still accept the validity of one of the theorems. For example, if the reader cannot accept Axiom 5 , he can still accept all of the reasoning and implications of Theorem 1.

${ }^{108}$ Simple majority rule is defined in P. Frshburn, supra note 70, at 18. This article makes no suggestion that it would be easy for the FCC to use a majority-rule process. In fact, the FCC might only be able to approximate such a process by using representative surveys. In addition, there may be some doubts regarding the institutional propriety of the FCC's using majority rule. See text at notes 114-115 infra. 
of listeners prefer each of two formats, resulting in a tie, then the public interest is in equipoise and the FCC "chooses" both formats.

Theorem 2: The FCC's choice of format can satisfy Axioms 1, $2 A, 3$, and 5 if and only if the choice process operates as majority rule with tie breakers. ${ }^{109}$ Majority rule with tie breakers operates exactly like simple majority rule if the number of people who prefer the old format does not equal the number of people who prefer the new. If there is a tie between the two groups of listeners, then the FCC uses a tie breaker rule. ${ }^{110}$

Theorem 2 states that if the FCC uses a choice process that is based on listener preferences, that regards listeners as fungible, that regards formats as fungible if there is no tie, that does not count any listener's desires negatively, and that chooses exactly one format, then that process is majority rule with tie breakers.

Theorems 1 and 2 are important because the D.C. Circuit has explicitly precluded the FCC from using a majority rule choice process. In Citizens Committee v. FCC, ${ }^{111}$ the seminal formatchange case, the court ruled that "[t]he Commission's judgmental function does not end simply upon a showing that a numerical majority prefer the Beatles to Beethoven, impressive as that fact may be in the eyes of the advertisers."112 The D.C. Circuit based this

100 Theorem 2 corresponds to Theorem 6.2 in P. FishBURN, supra note 70, at 65 . For a mathematical explanation, see $i d$. In layman's terms, Axioms 1, 2A, 3, and 5 combine to produce majority rule with tie breakers, because of the following line of reasoning. Assume that the FCC is choosing between format X and format $\mathrm{Y}$, that $a$ listeners prefer $\mathrm{X}, b$ listeners prefer $\mathrm{Y}$, and that $a$ is less than $b$. Axiom 5 requires the FCC to choose either X or $\mathrm{Y}$, but not both. If the FCC were to choose $\mathrm{X}$, then it would have to violate Axiom $1,2 \mathrm{~A}$, or 3. To see this, assume that one person who prefers $Y$ changes his preference to $X$. Hence, now $a+1$ listeners prefer $X$ and $b-1$ listeners prefer $Y$. Under Axiom 3, the FCC must continue to choose $\mathrm{X}$. If $b-a$ listeners who used to prefer $\mathrm{Y}$ change preferences to $\mathrm{X}$, Axiom 3 would continue to require the FCC to choose $X$. If such changes occurred, $b$ listeners would prefer $\mathrm{X}$ and $a$ listeners would prefer $\mathrm{Y}$. If all listeners had reversed their preferences, however (so that $b$ listeners preferred $X$ while $a$ listeners preferred $\mathrm{Y}$ ), Axiom 2A would require the FCC's choice to reverse to $Y$. This shows that under a nonmajority system, with $b$ listeners preferring $\mathrm{X}$ and $a$ listeners preferring $\mathrm{Y}$, the FCC would sometimes choose $\mathrm{X}$ and sometimes choose $\mathrm{Y}$. This contradicts Axiom 1, which asserts that listeners are fungible. Thus our original assumption, that $X$ can be chosen when more listeners preferred $Y$, must have been wrong. Therefore, we have shown that whenever the number of listeners preferring one format is greater, Axioms 1, 2A, 3, and 5 require the FCC to choose that format.

If there is a tie, then Axiom 5 demands that a single choice still be made, and Axiom 1 only allows numbers of listeners to affect the choice. Hence, the FCC must make an essentially arbitrary choice, that is, it must use a tie breaker.

110 One such method might be deciding all ties in favor of the old format.

111436 F.2d 263 (D.C. Cir. 1970).

112 Id. at 269. See also Citizens Comm. to Save WEFM v. FCC, 506 F.2d 246, 252, 260- 
rule on the FCC's duty to.make certain that the airwaves, a commonly held resource, are used to effect the greatest good for the greatest number, including minorities. ${ }^{113}$ Alternatively, the rule could be based on the administrative unfeasibility of collecting data on all of the listeners' preferences. ${ }^{114}$ Further, one might question the institutional propriety of the FCC's use of direct listener "votes" to choose a format; it is not usually a function of administrative expertise to hold "elections." Regardless of the philosophical basis of the quoted language, the rule precludes the FCC from using either simple majority rule or majority rule with tie breakers. ${ }^{115}$ Since the FCC may not use simple majority rule, it must violate at least one of Axioms 1,2,3, and 4. Since the FCC may not use majority rule with tie breakers, it must violate at least one of Axioms 1, 2A, 3, and 5 .

By combining these two deductions with the discussion of the individual axioms above, one can show that the FCC must violate at least one of Axioms 1 and 2A. One can make this deduction from Theorem 2 alone. Because the D.C. Circuit has already prohibited majority rule with tie breakers, and because Axioms 3 and 5 are likely to be imposed on the FCC by the court, ${ }^{116}$ the Commission must violate at least one of Axioms 1 and 2A. Theorem 1 partially reinforces this result. If the FCC is legally precluded from violating Axioms 3 and $4,{ }^{117}$ then (regardless of the reader's view of the likelihood that Axiom 5 constitutes a legal constraint) Theorem 1 tells us that the FCC must violate either Axiom 1 or 2. The only way in which the FCC might violate Axiom 2 and not Axiom $2 \mathrm{~A}$ would be if the Commission were to use tie breaker rules. If we put this possibility to one side, then the FCC must violate Axiom 1 or 2A. This result partially explains and justifies the FCC's reluc-

61 (D.C. Cir. 1974) (en banc).

${ }^{113}$ Citizens Comm. v. FCC, 436 F.2d 263, 269 (D.C. Cir. 1970).

114 WNCN Listeners Guild v. FCC, 610 F.2d 838, 862 (D.C. Cir. 1978) (en banc)

(Tamm, J.; dissenting), cert. granted, 100 S. Ct. 1273 (1980).

${ }_{115}$ It should also be noted that if, as is likely, the D.C. Circuit imposes Axiom 5 on the FCC, see text and notes at notes 103-104 supra, the need for tie breakers would result in a violation of Axiom 2. Because that is a necessary condition of Theorem 1, requiring Axiom 5 , by itself, would preclude simple majority rule. On the other hand, Axiom 4, while not a necessary condition to majority rule with tie breakers, would not cause any violation of the axioms that are essential to Theorem 2. Therefore, even if Axiom 4 were not to be imposed as a legal constraint, see text and notes at notes 99-102 supra, Theorem 2 may remain completely valid.

${ }_{116}$ See text and notes at notes 97-104 supra.

117 See id. 
tance to accept the WEFM doctrine: the need to choose between formats leaves the FCC no appealing options. Because the Commission must choose between violating Axioms 1 or $2 \mathrm{~A}$, the FCC must either accord greater weight to the views of members of certain groups, give a preference to the status quo where the numbers of listeners who prefer each format are not equal, prefer certain formats for purely paternalistic reasons, or use data on intensity of listeners' preferences to make a choice. ${ }^{118}$ This article suggests that the first approach is burdened by substantial and unexplored legal difficulties; the second is difficult to implement and might be voided, as a matter of law, by the courts; the third may have serious difficulties under the first amendment; and the last option is impracticable. ${ }^{119}$ In sum, the WEFM doctrine probably will be plagued either by administrative impracticalities or by substantial legal uncertainties. In contrast, the FCC's policy of unfettered licensee choice of format would be easy to implement and, for that reason alone, the Commission prefers unfettered licensee choice to the WEFM doctrine.

A policy analyst should also be extremely wary of accepting WEFM. To understand this, consider the nature of the burdens that must be shouldered by one who would argue for the WEFM doctrine. Since Axioms 3 and 5 are likely to be imposed as legal constraints, the WEFM proponent must be prepared to choose from among the four methods of violating Axioms 1 or 2A. This article has already shown, however, that the FCC cannot practicably use data on intensity of listener preferences to choose a format. Hence, a supporter of the WEFM doctrine must be prepared to choose from among the remaining three alternatives. To justify any such choice, the WEFM advocate must argue not only for the legality (and the practicability) of one of the alternatives, but must also present persuasive normative arguments for according greater weight to the views of members of certain groups, or for giving a preference to the status quo, or for preferring certain formats for paternalistic reasons. As yet, neither the FCC nor the D.C. Circuit has even considered, much less analyzed, any of these alternatives in the WEFM setting, nor has any commentator offered strong arguments in favor of them. Until such arguments are advanced, the critical policy analyst should be reluctant to embrace WEFM.

116 These are the possible ways to violate either Axiom 1 or Axiom 2A, see text and notes at notes 72-96 supra.

11. See id. See also Plott, supra note 66, at 539-43. 


\section{Renewal Hearings and WEFM}

The WEFM doctrine also causes difficult problems, beyond those discussed above, for license renewal hearings. This part briefly describes the structure and theory of broadcast license renewal hearings and then, using axiomatic social choice theory, analyzes the implications of the WEFM doctrine in the renewal setting.

\section{A. Broadcast License Renewals}

When a broadcaster's license expires ${ }^{120}$ he must obtain a renewal from the FCC before he may lawfully continue operating. The FCC may grant the license renewal only if it would "serve the public interest, convenience and necessity."121 The WEFM doctrine may affect renewals in two ways. First, if a licensee abandons a unique, viable format during his term of license, and that abandonment is protested by a significant sector of the listening public, the FCC appears to be obliged to hold a hearing at renewal time on whether the abandonment was in the public interest. ${ }^{122}$ Such a hearing, which would be triggered by a petition to deny the renewal, is subject to an analysis identical to that already performed using social choice theory, ${ }^{123}$ and is plagued by all of the problems that analysis revealed. Second, at license renewal time, the renewal applicant may be challenged by other applicants for the license. If the application is challenged, the FCC must hold a comparative hearing ${ }^{124}$ and select either the renewal applicant or one of the challengers to receive the license. The WEFM doctrine causes substantial problems with respect to such comparative hearings.

The FCC conducts broadcast license renewal comparative hearings under the Policy Statement on Comparative Broadcast Hearings ${ }^{125}$ ("1965 Policy Statement"). The 1965 Policy Statement

${ }^{120}$ Most licenses expire after three years. 47 U.S.C. $\S 307$ (d) (1976).

121 Id. \& 309.

122 This is because a "grant" of a license is the focus of both a renewal and transfer hearing, and a "grant" is authorized only if it would serve the public interest. Id. $\S 309$. The FCC and the D.C. Circuit agree that such hearings would be necessary. See text and notes at notes 53,57 supra.

${ }^{123}$ See Part II supra.

${ }^{124}$ Citizens Communications Center v. FCC, 447 F.2d 1201 (D.C. Cir. 1971).

${ }^{125} 1$ F.C.C.2d 393 (1965) [hereinafter cited as 1965 Policy Statement]. The 1965 Policy Statement originally was intended to define and describe the content of initial broadcast license comparative hearings. In 1970 the FCC formulated the Policy Statement Concerning Comparative Hearings Involving Regular Renewal Applicants, 22 F.C.C.2d 424 (1970) [here- 
describes six decisional criteria used to determine which of the competing applicants should get the license. The FCC compares and ranks each of the applicants under each of the criteria, and then combines the rankings to choose the best licensee. ${ }^{128}$

A "factor of primary significance" is the diversification of control of the media. ${ }^{127}$ Applicants without any other media interests are preferred to those who have such interests, because diversifying control of the media is believed to increase the flow of information to the public. ${ }^{128}$ The more complete the applicant's control of any other media outlets and the closer to the location of the proposed license and the more powerful those outlets are, the more the applicant is disfavored. ${ }^{22}$

inafter cited as 1970 Policy Statement]. The 1970 Policy Statement attempted to narrow drastically the circumstances under which a renewal applicant would be denied renewal. As long as the broadcaster had provided "strong" or "solid" programming, the FCC proposed to renew the license, regardless of how appealing any challenger might appear. The D.C. Circuit invalidated the 1970 Policy Statement, holding that it failed to accord challengers the "full hearing" to which they were entitled under section 309(e) of the Communications Act of 1934, 47 U.S.C. \& 309(e) (1976). Citizens Communications Center v. FCC, 447 F.2d 1201 (D.C. Cir. 1971). Since that time the FCC has not specially promulgated any new rules or policies pertaining specifically to renewal hearings, see, e.g., Formulation of Policies Relating to the Broadcast Renewal Applicant, Stemming from the Comparative Hearing Process, 66 F.C.C.2d 419 (1977), and the 1965 Policy Statement has governed renewal hearings by default. See Central Fla. Enterprises v. FCC, 598 F.2d 37, 50 (D.C. Cir. 1978), cert. dismissed, 441 U.S. 957 (1979).

${ }^{126}$ See generally Spitzer, supra note 67, at 734-38. The FCC compares only applicants who previously have passed the application phase. In that phase, the FCC's Broadcast Bureau examines applicants' legal, financial, technical, and moral soundness to determine which applicants are minimally qualified. See Anthony, Towards Simplicity and Rationality in Comparative Broadcast Licensing Proceedings, 24 Stan. L. Rev. 1, 18-24 (1971). Other factors related to the public interest are also reviewed. See id. at 19-24. The Chief of the Broadcast Bureau then decides which minimally qualified applicants merit a comparative hearing. See id. at 34 .

The FCC appears to be breaking away from this ordering process of applicant selection where the applicants are "equally qualified to hold the license"; applicants in the future will be selected by lottery. Pick an Applicant, Any Applicant, Brondcasting Magaznne, June 9, 1980, at 30. Cf. Star Television, Inc. v. FCC, 416 F.2d 1086, 1094-95 (D.C. Cir. 1968) (Leventhal, J., dissenting) (lottery method discussed as acceptable for television station construction permits, where applicants are "all reasonably qualified"), cert. denied, 396 U.S. 888 (1969). The constitutionality of such a selection method remains untested.

1271965 Policy Statement, supra note 125, at 394.

128 See id. at 394 n.4.

129 Id. at 395-96. The description in the 1965 Policy Statement focuses on industry structure as the key to diversifying control of the media. The D.C. Circuit recently rebuffed the FCC's attempt to downplay a challenging applicant's superiority under the diversification criterion in Central Fla. Enterprises, Inc. v. FCC, 598 F.2d 37, 53-54 (D.C. Cir. 1978), cert. dismissed, 441 U.S. 957 (1979). The court, unlike the FCC, found that the geographical remoteness of the renewal applicant's other media interests and the managerial autonomy the local station enjoyed did nothing to minimize the importance of this criterion. Id. 
Combining ownership and management ("integration") is another factor of "substantial importance." "1so Applicants planning unified ownership and management are preferred to those that separate the functions. Such integration is believed to improve a station's ability to comply with its legal obligations, as well as its flexibility with regard to its listeners' changing needs. ${ }^{131}$

A third criterion, proposed program service, is usually given no weight. While comparative evaluation of program plans is vital to the public, it is impractical unless the plans exhibit significant differences. ${ }^{132}$

The FCC also usually ignores the criterion of past broadcast records under other licenses. It normally considers only unusually good or bad records, ${ }^{133}$ as these extremes are very likely to foreshadow the applicant's future performance. The FCC does not use this general approach to evaluate the renewal applicant, however, for the renewal applicant's performance during the past term is always the best indicator of likely future performance under the same license. This contrasts with the applicant for a new license, whose past broadcast experience may have been acquired under conditions which make it irrelevant to the proposed license.

But when the FCC explicitly attempted to make the renewal applicant's performance during the preceeding term a totally noncomparative factor which would outweigh all comparative factors in renewal hearings, the D.C. Circuit quickly rebuffed the attempt. ${ }^{134}$ Further, when the FCC recently acted as if the renewal applicant's record were a totally noncomparative factor, capable of overcoming the challenging applicant's advantages under the comparative criteria, the D.C. Circuit vacated the license award and remanded the case to the Commission. ${ }^{135}$ Although the court simultaneously invited the FCC to develop explicitly some noncomparative renewal factors, the tenor of the opinion casts doubt on the FCC's practical and legal abilities to do so. ${ }^{136}$

1s0 1965 Policy Statement, supra note 125, at 395-96.

${ }^{132}$ It should be noted that a number of factors, such as past experience, location of residence, and so on affect the ranking under this criterion. See id.; Anthony, supra note 126 , at 29 n.169.

1321965 Policy Statement, supra note 125, at 397.

138 Id. at 398.

134 See note 125 supra.

${ }^{1 s s}$ Central Fla. Enterprises, Inc. v. FCC, 598 F.2d 37 (D.C. Cir. 1978), cert. dismissed, 441 U.S. 957 (1979).

1se See generally id. 
Finally, the FCC favors applicants proposing technically superior service ${ }^{132}$ and disfavors those with serious defects in character. ${ }^{138}$ All minimally qualified applicants are then ranked under each applicable criterion. ${ }^{138}$ Those rankings are combined in an "inherently complex" process which "does not lend itself to precise categorization or to the clear making of precedent."140 This complexity is increased by the fact that the importance of each criterion varies with the hearing's factual context. ${ }^{141}$

\section{B. The Effect of WEFM}

The WEFM doctrine would change broadcast license renewal comparative hearings ("renewal hearings") by injecting another criterion into the hearing process. Assume that at least one of the license applicants at a renewal hearing, either the renewal applicant or a challenger, proposes service involving a unique format. The WEFM doctrine would apparently require the FCC to rank the alternative proposed formats in terms of their efficacy in serving the public interest before the Commission lawfully could grant a broadcast license. If a format, once adopted, is protected to the extent WEFM indicates, then it must be necessary to ensure that the best format is adopted in the first place. The format ranking presumably would be combined with the rankings under the other criteria in selecting the best licensee. As the discussion below demonstrates, however, the FCC would have great difficulty in ranking the formats.

\section{Axioms}

This part of the article presents a set of axioms that limit, in varying manners and degrees, the FCC's ranking of formats. The

1371965 Policy Statement, supra note 125, at 398-99.

138 Id. at 399. Short of serious defects, character evidence is excluded to prevent the hearing from degenerating into attacks on minor personality flaws. See id.

139 In general, a ranking is a statement within a particular criterion that one applicant is best, another applicant is second best, a third applicant is third best, and so on down to the least desirable applicant. See Axiom 1', text at note 145 infra, for a more thorough discussion. In this context, the ranking is sometimes ordinal. That is, it specifies the order in which applicants are ranked but gives no other information. At other times, the ranking will hint at how much one applicant is preferred over another. See, e.g., Mid-Florida Television Corp., 33 F.C.C.2d 1, 21 (1972) (degree of preference under various criteria described as "small" or "substantial").

1401965 Policy Statement, supra note 125 , at 393.

163 Id. 
axioms are then combined into a theorem that reveals some fundamental problems in attempting to rank formats on the basis of listener preferences. The axioms may represent either physical or legal constraints on the ranking of formats, ${ }^{142}$ just as in the analysis of license transfer proceedings. ${ }^{143}$ Many of the legal constraints must be derived as corollaries to established rules governing the general conduct of renewal hearings because of the paucity of format cases. Such constraints ensure that the FCC complies with applicable statutes, uses procedures that satisfy the minimal standards of procedural due process, including following its own precedents, and employs "reasoned decision making" rather than "arbitrary and capricious" methods. ${ }^{144}$

Axiom 1': The FCC's ranking of formats is:

(a) unique-the FCC must make exactly one ranking of formats in each case;

(b) total-the FCC must find, by any appropriate means, that, between any two formats, $X$ and $Y$, either $X$ will serve the public interest at least as well as $Y$, or $Y$ will serve the public interest at least as well as $X$, or $X$ and $Y$ will serve the public interest equally well;

(c) transitive-if, for any three formats, $X, Y$, and $Z, X$ will serve the public interest at least as well as $Y$, and $Y$ will serve the public interest at least as well as $Z$, then the FCC must find that $X$ will serve the public interest at least as well as $Z^{145}$

Axiom 1' probably is a legal constraint on the FCC for at least two reasons. First, and most important, Axiom 1' will represent an application of the proscription of arbitrary and capricious decision making by an administrative agency. ${ }^{146}$ Consider the following:

(a) $\mathrm{X}$ would serve the public interest better than would $\mathrm{Y}$

\footnotetext{
${ }^{142}$ See Spitzer, supra note 67, at 736-38, for a detailed definition of these types of constraints.

14s See Part II supra.

146 See, e.g., Greater Boston Television Corp. v. FCC, 444 F.2d 841, 850-51 (D.C. Cir. 1970). For a fuller development of these ideas, see Spitzer, supra note 67, at 737-38.

${ }^{145}$ For completeness, one must add: reflexive-the FCC must find that any format would serve the public interest at least as well as itself. See note 161 infra.

148 The D.C. Circuit is willing to interfere in the FCC's construction of rankings when the court believes the rankings to be arbitrary. See Central Fla. Enterprises, Inc. v. FCC, 598 F.2d 37 (D.C. Cir. 1978), cert. dismissed, 441 U.S. 957 (1979). The Administrative Procedure Act specifically authorizes the judiciary to hold any arbitrary or capricious administrative agency action unlawful. 5 U.S.C. \& 706(2)(a) (1976).
} 
and $\mathrm{Y}$ would serve the public interest better than would $\mathrm{X}$.

(b) $\mathrm{X}$ would not serve the public interest at least as well as $\mathrm{Y}$ and $\mathrm{Y}$ would not serve the public interest at least as well as $\mathrm{X}$.

(c) $\mathrm{X}$ would serve the public interest at least as well as $\mathrm{Y}$, and $\mathrm{Y}$ would serve the public interest at least as well as $\mathrm{Z}$, but $\mathrm{X}$ would not serve the public interest at least as well as $\mathrm{Z}$.

Each of these findings would violate the corresponding portion of Axiom 1', and each is perverse. Indeed, if there is any content to the concepts of serving the public interest "as well" or "better," then the statements in (a) through (c) logically cannot constitute reasoned decision making. Hence, each of the sample findings would be unlawful, as would any other findings that violated any of the sections of Axiom 1'.

Second, the FCC's rankings of applicants have, historically, conformed to the requirements of Axiom 1..147 A departure from established practice without explanation would violate the requirements of procedural due process. Hence, for the moment at least, the FCC is legally required to act in accordance with Axiom 1'.

Axiom 2': There are at least three different potential formats that applicants might propose to broadcast over the station's facilities, each of which would be acceptable if actually proposed and if no better format were actually proposed. Axiom 2r is a physical constraint. It asserts that there are at least three minimally acceptable potential formats in the world, ${ }^{148}$ but makes no claim respecting the number of formats the FCC must actually rank in any particular case. An acceptable format is defined as one that, if broadcast, would benefit the public interest. An unacceptable format is one that would not serve the public interest, even as an alternative to silencing the station. For example, a format including nothing but obscene material might be unacceptable. ${ }^{149}$

Axiom 3': The FCC can consider any possible set of listener tastes and produce a ranking of the formats thereon. Axiom $3^{\prime}$ is

147 See, for example, the rankings in RKO Gen., Inc., 44 F.C.C.2d 123, 136-37 (1973) (ranking adopted was unique and total); Theodore Granik, 8 F.C.C.2d 1068, 1079 (1967) (same). Although the FCC may fail on occasion to provide an explicit comparision of two applicants under a criterion, and hence appear to violate Axiom $1^{\prime}(\mathrm{b})$ (totality), it does so only in cases where use of Axiom $1^{\prime}$ (c) (transitivity) would allow one to deduce the missing comparison.

148 For a hint of the large number of potential formats that might be proposed, see Brenner, supra note 81 , at 93.

11" Cf. FCC v. Pacifica Foundation, 438 U.S. 726 (1978) ("indecent" language). 
also probably a legal constraint on the FCC's behavior. It merely asserts that the FCC will always make findings regarding how well the alternative formats would serve the public interest. Although Axiom 3' does not specify the form of the rankings, it prevents the FCC from refusing to make any rankings even if the listeners' tastes are spread evenly over the alternative formats. In short, Axiom 3' represents the core philosophy of the WEFM doctrine. A refusal to rank the alternative formats in renewal hearings would correspond exactly to the FCC's reluctant behavior in the license transfer context. In order to be consistent, the D.C. Circuit would have to reverse any case characterized by such diffidence on the part of the Commission. ${ }^{150}$ The court would base its reversal upon the FCC's statutory duty to award broadcast licenses that serve the public interest. In the absence of such rankings, the court could not tell if this had been done. ${ }^{151}$

Axiom 4": The FCC uses no absolute scales of intensity of preference to rank formats. Axiom 4', a physical constraint, restricts the types of information the FCC can use in constructing the rankings. The Commission may not use absolute scales of intensity of preference which attach unique numerical indices to listeners' preferences for various formats. Nor may it make pairwise comparisons of intensities of preference between different listeners because such comparisons would require the use of an absolute scale. For example, the FCC may not use such statements as "Listener A's preference for format $X$ over format $Y$ measures 18 utiles" or "Listener A's preference for format $X$ over format $Y$ is twice as strong as Listener B's preference for format $W$ over format Z." Quaternary comparisons, such as "Listener A's preference for format $X$ over format $Y$ is twice as strong as his preference for format $W$ over $Z$ " are permitted under Axiom 4' because they depend solely on the listeners' subjective rankings and hence do not require an absolute scale to make the comparison. The difficulty of using intensity of preference data to make decisions was reviewed in the discussion of Axiom $1^{182}$ and need not be repeated at this point.

Axiom 5': No single listener's tastes completely determine the

${ }^{180}$ Compare the court's reaction to such diffidence in the license transfer context in WNCN, discussed in text and notes at notes 54-65 supra.

${ }^{131}$ See Central Fla. Enterprises, Inc. v. FCC, 598 F.2d 37, 50 (D.C. Cir. 1978), cert. dismissed, 441 U.S. 957 (1979), on the need for the FCC's decisions to be susceptible to meaningful judicial review.

182 See text and notes at notes 78-85 supra. 
FCC's rankings. This axiom merely prevents the Commission from always ranking all of the alternative formats on the basis of one listener's desires. As long as no single listener's tastes determine the rankings in every possible situation, Axiom $5^{\prime}$ will not be violated.

Axiom 5' probably models a legal constraint on FCC activity. The format cases have explicitly argued that radio entertainment must provide the "greatest good for the greatest number."163 Consequently, if there are too few devotees of a particular format, then they may have no claim to the airwaves. The D.C. Circuit has also intimated that the FCC should survey listening areas to determine listener tastes and preferences. ${ }^{154}$ These statements strongly suggest that the FCC will not be allowed to base a ranking of formats on the tastes of any one listener. Such a ranking would be voided because of a failure to engage in reasoned decision making.

Axiom 6': If, for any two formats $X$ and $Y, Y$ is preferred over $X$ by all listeners, then the FCC may not rank $X$ as highly as $Y$. Axiom 6' merely prevents the FCC from finding that X would serve the public interest as well as would $\mathrm{Y}$ if listeners unanimously prefer $\mathrm{Y}$. The axiom does not require unanimous listener preference before the FCC may rank formats. As such, it represents a legal constraint on the Commission. The D.C. Circuit has stated that the FCC may not totally disregard minority tastes, ${ }^{185}$ that gratification of listeners' desires serves the public interest, ${ }^{158}$ and that format hearings are needed because the radio market "is an imperfect reflection of listener preferences."157 Violating Axiom $6^{\prime}$ ' would ignore all tastes, gratify no one's desires, and totally fail to "reflect" listener preferences. The D.C. Circuit would vacate any license award based upon such a ranking, either as arbitrary and capricious or as a failure to conform to the public interest standard of the Communications Act of 1934..$^{168}$ 1973).

283 Citizens Comm. to Keep Progressive Rock v. FCC, 478 F.2d 926, 933 (D.C. Cir.

164 Id. at 934.

1ss Id. at 926, 929 n.7.

1se Citizens Comm. to Save WEFM v. FCC, 506 F.2d 246, 268 n.34 (D.C. Cir. 1974).

${ }^{182}$ WNCN Listeners Guild v. FCC, 610 F.2d 838, 851 (D.C. Cir. 1979) (en banc), cert. granted, $100 \mathrm{~S}$. Ct. 1273 (1980).

${ }^{238}$ In addition, there are FCC decisions holding that an applicant ranked equal to or above the other applicants in a comparative hearing should be awarded the license. See, e.g., Paul J. Molnar, 30 F.C.C. 272 (1961); Great Lakes Television, Inc., 25 F.C.C. 470, 529 (1958). This supports the corollary that a format preferred by all listeners should be found to serve the public interest best. 
Axiom 7': In any given decision, ${ }^{159}$ for any four formats $W, X$, $Y$, and $Z$, if each listener's preferences relate $W$ to $X$ in exactly the same way (that is, by exactly as much) that his preferences relate $Y$ to $Z$, then if $W$ is not ranked at least as high as $X, Y$ will not be ranked as high as $Z$. Axiom $7^{\prime}$ guarantees that formats are fungible with respect to the public interest. Having first determined the listener's preferences for formats, one has also determined how the formats rank with respect to the public interest. The name and content of the format are irrelevant. Axiom $7^{\prime}$ is the exact analog of Axiom 2. ${ }^{160}$ Both Axiom 7' and Axiom 2 preclude paternalism and granting the status quo a preference. The discussion of Axiom 2 reviewed at length the potential legal and practical problems that plague any attempt to use paternalism or a preference for the status quo. That discussion revealed that although giving a preference to the status quo is probably illegal in a license renewal setting, the legality of paternalistic format choice is less certain. Hence, depending on the legality of paternalism, Axiom 7' might represent either a legal or practical physical constraint.

Theorem 3: No ranking process can simultaneously satisfy Axioms $1^{\prime}, 2^{\prime}, 3^{\prime}, 4^{\prime}, 5^{\prime}$, and $7^{\prime} .{ }^{161}$ This theorem means merely that

150 The focus of Axiom $7^{\prime}$ is on a single moment so that the same policies apply to each pair of formats.

${ }^{100}$ See text and notes at notes 86-94 supra. This article has already noted that both the FCC and the D.C. Circuit seem to assume that listener preferences determine the public interest. See text and note at note 69 supra. To the extent that listener preferences completely determine the public interest, Axiom 7' may model a legal constraint. This article contrasts determination of the public interest by listener preferences with determination of the public interest by paternalism.

101 This is an example of what is known as a "possibility theorem," even though it proves that it is impossible for a process to satisfy certain axioms simultaneously. See A. SEN, supra note 78 , at $37-40$. The proof of the theorem is easily derived from the proof contained in Appendices B and C to Spitzer, supra note 67, at 768-78, by making the necessary substitutions:

Notation:

$\mathbf{E}=$ the set of all acceptable formats

$v=$ the set of formats that the FCC is considering (this is a subset of E)

$\mathrm{N}=$ the set of all listeners

$\mathrm{U}=$ the set of all real valued functions of $\mathrm{EX} \mathrm{N}$.

Given $a, b \varepsilon v ; u \varepsilon U, u\left(a, c_{i}\right) \geq u\left(b, c_{i}\right)$ means that citizen $i$ likes listening to format a at least as well as format $b$.

The following correspondences obtain between axioms employed in this article and those (denoted by italicized axiom numbers) presented in Appendix B to Spitzer, supra note 50, at 768-72:

Axiom 1' corresponds to Axioms 1,5, and 7. Because Axioms 1 and 7 combined to produce lemma 1, Axiom 1' also subsumes the lemma. Axiom 1' can be expressed: $1^{\prime}$. There is a ranking $R(v, u)$ between the formats, depending only on $v$, the set of formats under 
the FCC's ranking of alternative formats must violate at least one of the axioms. The ranking process may violate more. That is to say, any process that produces a ranking that accords with notions of serving the public interest "better" (Axiom 1') and that can handle the different possible preferences of listeners (Axiom $3^{\prime}$ ) for the numerous different formats that might be broadcast (Axiom $2^{\prime}$ ) (all of which a $W E F M$ hearing must do by definition) must violate one of the other four axioms. It must either mirror only one listener's preferences (Axiom 5'), or sometimes rank formats in an order opposite to the unanimous preference of all listeners (Axiom 6 '), or use paternalistic notions of a "good" format or a preference for the status quo (Axiom $7^{\circ}$ ), or use information on intensities of preference in constructing the ranking (Axiom $4^{\prime}$ ).

For example, the FCC might use a type of majority rule criterion to rank formats. It could set up an agenda of pairwise comparisons, declare the format preferred by most listeners to be the winner, and then pit the winner against another proposed format. The winner of the last pairing would be ranked first. Assume that there are four formats, $\mathrm{W}, \mathrm{X}, \mathrm{Y}$, and $\mathrm{Z}$. $\mathrm{W}$ will first be compared to $\mathrm{X}$, with the winner then compared to $Y$, and that winner finally compared to Z. Finally, there are the three listeners. Listener One prefers $\mathrm{Y}$ to $\mathrm{X}$ to $\mathrm{W}$ to $\mathrm{Z}$. Listener Two prefers $\mathrm{X}$ to $\mathrm{W}$ to $\mathrm{Z}$ to $\mathrm{Y}$.

consideration by the FCC, and on the numbers assigned to each alternative for each individual by function $u$. $R$ is:

(i) unique

(ii) reflexive ( $\forall \times \varepsilon E, x R x$ )

(iii) total ( $\forall x, y \varepsilon E$, $x R y$ or $y R x)$

(iv) transitive ( $\forall x, y, z \in E, x R y$ and $y R z \Rightarrow x R z$ ).

Axiom 2' corresponds to Axiom 2 and can be expressed: 2 . $|E| \geq 3$.

Axiom $3^{\prime}$ corresponds to Axiom 3 and can be expressed: $3^{\prime} . R\left(v, u^{i}\right)$ is defined $\forall v, \forall u^{i} \varepsilon$ U.

Axiom 4' corresponds to Axiom 4 and can be expressed: $4^{\prime}$. For every $u^{1}, u^{2} \varepsilon U, \forall v \subseteq$ $\mathrm{E}$, if $\exists \mathrm{n}+1$ numbers, $\alpha, \beta_{1}>0, \beta_{2}>0, \ldots, \beta_{\mathrm{n}}>0$ such that $\forall \mathrm{c}_{\mathrm{i}} \varepsilon \mathrm{N}$, and $\forall \mathrm{a} \varepsilon \mathrm{E}$, $\mathrm{u}^{1}\left(\mathrm{a}, \mathrm{c}_{\mathrm{j}}\right)=\alpha+\beta_{\mathrm{i}} \mathrm{u} 2\left(\mathrm{a}, \mathrm{c}_{\mathrm{i}}\right)$ then $\mathrm{R}\left(\mathrm{v}, \mathrm{u}^{1}\right)=\mathrm{R}\left(\mathrm{v}, \mathrm{u}^{2}\right)$.

Axiom $5^{\prime}$ corresponds to Axiom 6 and can be expressed: $5^{\prime}$. $\exists$ no $i$ such that $\forall a, b \varepsilon E$, $\mathrm{u}\left(\mathrm{a}, \mathrm{c}_{\mathrm{j}}\right)>\mathrm{u}\left(\mathrm{b}, \mathrm{c}_{\mathrm{i}}\right) \Rightarrow \sim \mathrm{bRa}$.

Axiom $6^{\prime}$ corresponds to Axiom 8 and can be expressed: $6^{\circ}, \forall v \underline{G E}$, if $a, b \varepsilon v$ and if $u(a$, $\left.c_{i}\right)>u\left(b, c_{i}\right) \forall i$ then $\sim$ bRa.

Finally, Axiom 7' corresponds to Axiom 9 and can be expressed: $7^{\circ}: \forall \mathrm{a}, \mathrm{b} \varepsilon \mathrm{E}, \dot{\forall} \mathbf{u}^{1} \varepsilon \mathrm{U}$, if $w, z \varepsilon E$ and $u^{0} \varepsilon U$ such that $\forall c_{i} \varepsilon N, u^{1}\left(a, c_{i}\right)=u^{0}\left(w, c_{i}\right)$ and $u^{1}\left(b, c_{i}\right)=u^{0}\left(z, c_{i}\right)$ then if $\sim \mathrm{zR}\left((\mathrm{w}, \mathrm{z}), \mathrm{u}^{0}\right)_{\mathrm{w}}$ then $\sim \mathrm{bR}\left((\mathrm{a}, \mathrm{b}), \mathrm{u}^{1}\right) \mathrm{a}$.

The ranking function is then substituted for the choosing function wherever the latter appears in the Appendices to Spitzer, supra note 67. Likewise, Axioms $1^{\prime}$ through $7^{\prime}$ are substituted for the appropriate corresponding Axioms 1 through 9. The immediate result is that no ranking can satisfy Axioms $1^{\prime}$ through $7^{\prime}$. 
Listener Three prefers $W$ to $Z$ to $Y$ to $X$. When $W$ and $X$ are first compared, $X$ will win. When $X$ is then compared to $Y, Y$ will win. When $Y$ is finally compared to $Z, Z$ will win. Hence, the FCC will rank $\mathrm{Z}$ first. But all listeners prefer $\mathrm{W}$ to $\mathrm{Z}$. This ranking process therefore violates Axiom 6'. A similar analysis can demonstrate that any proposed ranking process must violate at least one of the axioms.

This article's analysis suggests that each of Axioms $1^{\prime}$ through $6^{\prime}$ is either a physical or a legal constraint on the FCC. Axiom $7^{\prime}$ might represent a legal constraint, depending on the legality of paternalism. If it is not possible to offer compelling arguments (including basic public policy arguments sufficient to hurdle the reasoned decision making requirement) in favor of the legality of paternalistic format choice-and neither the court nor the FCC has even considered the issue-then Axiom $7^{\prime}$ will model a legal rule. Under such circumstances, the WEFM doctrine will force the FCC to choose between violating legal rules that are supposed to constrain its ranking of formats, and pretending to rely on preference intensity data, which is impractical. The FCC would, therefore, probably violate one of the legal rules and then obfuscate what it had done with a blizzard of doubletalk. To say the least, it is unseemly for the D.C. Circuit to place the agency in such an uncomfortable position. Violation of legal rules and subsequent obfuscation contravene important principles of administrative law. Citizens have a right to know of the workings of any administrative process that governs them. Obfuscation may preclude judicial review of whether the decision was "arbitrary and capricious."162 More important, it is a fundamental precept that an agency can only perform tasks validly delegated to it. Violation of a legal constraint necessarily places an agency beyond the limits of such a delegation. $^{\mathbf{1 6 3}}$

\section{IMPLICATIONS AND RECOMMENDATIONS}

The foregoing analyses cast considerable doubt upon the wis-

${ }^{162}$ This is essential, see notes 146,151 supra. There is a theory that when an allocative decision involves a clash of fundamental values, the clash should be resolved in a way that seems not to violate either value usually by disguising the actual sacrifice of one of them. See G. Calabresi \& P. Bobbitt, Tragic Choices 24-26, 57-58 (1978). It is unclear, however, that even under this theory, preservation of axioms which could be violated without leading to irrational decisionmaking, such as $4^{\prime}$ and $7^{\prime}$, is important enough to justify such trickery.

${ }^{163}$ See text and notes at notes 167-172 infra. 
dom of the WEFM doctrine. Theorems 1 and 2 indicated that implementing the doctrine in license transfer hearings will require the Commission to accord greater weight to the views of members of certain groups, to give a preference to the status quo, or to prefer certain formats for paternalistic reasons. Because neither the FCC nor the court has even considered these alternatives, Part II argued for extreme caution in accepting WEFM. Theorem $3 \mathrm{dem}-$ onstrates that, in the context of license renewal hearings, the doctrine may be worse. Unless one can show that paternalistic format choice is lawful, WEFM will induce the FCC to subvert its own legitimacy by acting illegally and then hiding its decisional process. Clearly, such results should be avoided.

The Commission's proposal, ${ }^{104}$ involving reliance on the broadcasters' choices of formats, might provide a superior alternative. First, licensee choice of format does not risk inducing the FCC to subvert its own legitimacy, as does WEFM. Second, although advertiser-supported radio programming, as a method of social choice, does not disprove Theorem 1,2, or 3, it may help to make these theorems appear less important in at least two respects. First, the values represented by some of the axioms may seem less fundamental in marketplace allocation, as opposed to allocation by administrative agency. For example, there may well be sentiment that an administrative agency should not allocate resources in ways that are biased in favor of wealthier listeners. ${ }^{165}$ People may not have such expectations about markets, where allocations traditionally are expected to be made on the basis of wealth. Even more fundamentally, the concept of a rational social choice, which seems so vital in the administrative setting, may not seem as important in the allocation of radio formats. Assume that there are five groups of listeners, numbered 1 through 5 , each with equal demographic appeal to advertisers. There are five formats, V, W, X, Y, and Z, each with identical production costs, and two stations, I and II. Everyone within each group has identical preferences.

\footnotetext{
14. See text and notes at notes 45-47 supra.

${ }^{185}$ See text and notes at notes 40-41, 78-79 supra.
} 


\begin{tabular}{l|ccccc}
\hline \hline Listeners & \multicolumn{5}{|c}{ Preference Order } \\
\hline Group 1 & V & W & X & Y & Z \\
\hline Group 2 & Z & V & W & X & Y \\
\hline Group 3 & Y & Z & V & W & X \\
\hline Group 4 & X & Y & Z & V & W \\
\hline Group 5 & W & X & Y & Z & V \\
\hline
\end{tabular}

If station I broadcasts V, and II broadcasts $W$, then groups 1 , 2,3 , and 4 will listen to I, while only group 5 will listen to II. In this situation, however, II will have an incentive to change its programming to format $\mathrm{Z}$. If it does so, it will attract groups $2,3,4$, and 5, while station I gets only group 1 . These format changes and the shifts in listenership between the stations are shown below.

\begin{tabular}{l|ll}
\hline \hline & STATION I & StATION II \\
\hline Initial formats & V attracts 1, 2,3,4 & W attracts 5 \\
Change 1 & V attracts 1 & Z attracts 2, 3, 4,5 \\
Change 2 & Y attracts 1,3,4,5 & Z attracts 2 \\
Change 3 & Y attracts 3 & X attracts 1, 2, 4, 5 \\
Change 4 & W attracts 1, 2,3,5 & X attracts 4 \\
Change 5 & W attracts 5 & V attracts 1, 2,3,4 \\
\hline
\end{tabular}

As can be seen, after five such changes formats $V$ and $W$ will once again be broadcast, except that the stations broadcasting them will be reversed. Such a result does not seem odd in the radio marketplace, given that stations are constantly altering formats. As a method of social choice, however, the marketplace has not made a "rational" choice of a "best" pair of formats. Instead, it has produced a format cycle.

Second, even if the values represented by the axioms still seem important, the marketplace obscures their fundamental inconsistency. Although the values are, and always will be, incompatible, advertiser-supported radio broadcasting does not focus listeners' attention upon the precise relationship between their preferences and the choice of broadcast formats to the degree that an administrative decision does. Whereas listeners may expect an administra- 
tive decision based upon their preferences, the marketplace interposes advertisers, broadcasters, and consumers between listeners' preferences and the decision to broadcast a particular format. In this manner, the need for an explicit "tragic choice"168 might be avoided.

Both of the last two arguments-the seeming unimportance of values in the marketplace and the tendency of the market to obscure the values' inconsistency-are premised on the notion that one should choose policies, at least in part, with respect to their appearance of fairness. To the extent that one disagrees with this premise, or agrees with it only weakly, he may reject both of the last two arguments. Further, if one were both to place a high value on honesty in government and to accept the values represented by the axioms, he might use both of the last two arguments to minimize the distinction between WEFM and unfettered licensee choice; WEFM risks obfuscation by the FCC while advertiser-supported radio represents obfuscation by the marketplace. However, regardless of how one evaluates these last two arguments, the first argument-that WEFM may induce the FCC to subvert its own legitimacy while licensee choice will not do so-retains its appeal. In sum, unless one can argue convincingly for paternalistic choice of formats, unfettered licensee choice probably is preferable to WEFM.

The problems with the WEFM doctrine ${ }^{187}$ basically arise from the juxtaposition of a delegation of power under the "public interest" standard with the "reasoned decision making" approach to judicial review. Theoretically, delegations of power to administrative agencies are valid only if subject to a standard under which courts may evaluate administrative actions intelligently. As a matter of practice, the Supreme Court upholds delegations of power that only direct the agency to serve the public interest. ${ }^{168}$ As the previous discussion suggests, such delegations of power provide virtually no substantive standards ${ }^{169}$ against which to test agency action. When a court tries to determine whether agency actions accord with the "public interest," the court must consider, to some extent,

168 See note 162 supra.

167 This discussion applies with equal force to other problems with the comparative hearing, which this author has previously discussed. See Spitzer, supra note 67, at 731-56.

${ }^{163}$ See generally McGowan, Congress, Court and Control of Delegated Power, 77 CoLUm. L. Rev. 1119 (1977).

169 Indeed, any delegation that represents a refusal to choose policies on the part of the Congress cannot provide a meaningful standard. See id. 
whether the questioned actions are "good" for society. In this manner, the courts therefore are necessarily drawn into the vortex of basic policy making whenever they try to evaluate the legality of agency actions that purportedly serve the public interest. At least in part out of a sense of institutional unease with such a role, the D.C. Circuit has developed its own version of a "reasoned decision making" requirement. Instead of focusing directly on the substantive sense of the agency's actions, this doctrine requires the agency to include various relevant considerations in the agency's "thought processes" that eventually produce the basic policy. Whereas the D.C. Circuit does not explicitly require the administrative agency to produce a policy that the court "likes," the reasoned decision making doctrine does demand that the agency arrive at a policy goal (such as serving the public interest) by combining smaller, more basic, relevant considerations in an inherently rational manner. In sum, a delegation of power under a "public interest" standard that is tested under the "reasoned decision making" standard of review leads the court to expect the FCC rationally to derive the public interest from a set of desirable criteria such as listeners' preferences. But social choice theory has shown that there is no way to accomplish such a task that accords both with minimum, common-sense notions of rationality and with the public interest.

Solutions to this dilemma could be sought in at least two different lines of thought. First, although the broad delegation of power to the FCC has been specifically approved by the Supreme Court, ${ }^{170}$ this article's analysis indicates that the courts perhaps ought to reexamine the constitutionality of the delegation. Alternatively, perhaps administrative action should be reviewed differently. The courts could back off from aggressive enforcement of the reasoned decision making doctrine. ${ }^{171}$ Some review functions could be transferred to the legislative or executive branches. ${ }^{172}$ Clearly, some change in institutional roles will be needed to resolve the WEFM dilemma and to deal with the basic problem from which it arises.

170 NBC, Inc. v. United States, 319 U.S. 190, 225-26 (1943).

${ }^{171}$ See Polsby, supra note 63.

172 See generally McGowan, supra note 168. The due process clause of the fourteenth amendment may limit, to some extent, the transfer of review functions away from the judiciary. L. JARpE, supra note 66 , at 381-89. 


\section{Conclusion}

The WEFM format doctrine requires the FCC to hold a hearing if a proposed license transfer would lead to the abandonment of a financially viable unique format and the proposed abandonment is protested by a significant segment of listeners. A social choice theoretical analysis shows that implementation of the WEFM doctrine will be burdened by substantial and unexplored practical and legal difficulties and, in the context of broadcast license renewal hearings, may induce the FCC to act illegally and then conceal its illegality. The Commission's alternative-reliance on unfettered licensee choice of radio formats-will not encourage the FCC to subvert its own lawfulness and therefore is superior to the WEFM doctrine. 